\title{
O PROBLEMA DA VERDADE EM KANT
}

\author{
Sara Sofia Lúcio Vargas ${ }^{1}$ \\ Faculdade de Letras da Universidade de Lisboa (FLUL) \\ https://orcid.org/0000-0002-7207-9788
}

\section{RESUMO:}

$\mathrm{O}$ presente artigo visa elucidar como o problema da verdade surge em Immanuel Kant a par da pergunta pelo critério de verdade, bem como assinalar a predominância deste. É com base na resposta a esta questão que, quanto ao autor, poderemos evitar incorrer em círculos dos quais se tornaria impossível sair. O problema assoma em como saber qual o critério de verdade? As reflexões remetem-nos para Kritik der reinen Vernunft e Prolegomena zu einer jeden kün ftigen Metaphysik, die als Wissenschaft wird auftreten können, mas essencialmente, para Logik: ein Handbuch zu Vorlesungen.

PALAVRAS-CHAVE: Conhecimento; Verdade; Verdade formal; Verdade material; Concordância.

\section{THE PROBLEM OF THE TRUTH IN KANT}

\begin{abstract}
:
This article aims to elucidate how the problem of truth arises in Immanuel Kant alongside the question of the criterion of truth, as well as pointing out its predominance. Based on the answer to this question we can avoid incurring in circles of which would become impossible to get out, regarding the author. The problem looms on how to know what is the criterion of truth? The reflections lead us to Kritik der reinen Vernunft and Prolegomena zu einer jeden kün ftigen Metaphysik, die als Wissenschaft wird auftreten können, but essentially to Logik: ein Handbuch zu Vorlesungen.
\end{abstract}

KEYWORDS: Knowledge; Truth; Truth formal; Material truth; Accordance.

\footnotetext{
${ }^{1}$ Doutoranda em Filosofia na Faculdade de Letras da Universidade de Lisboa (FLUL), Portugal. E-mailsvargas@campus.ul.pt
} 


\section{À guisa introdutória: da verdade à questão pelo seu critério}

A questão "o que é a verdade?" surge na mente humana, de uma maneira geral, pelo seu desiderato em alcançar um conhecimento seguro, no qual se confie, que seja verdadeiro. A verdade aparece, assim, como rótulo de confiança. Mas o que é mesmo a verdade?

Investigando Immanuel Kant, no seu pensamento crítico que atenta na importância de averiguar primeiro as formas e os limites das nossas faculdades cognitivas antes de se instituir qualquer sistema filosófico metafísico, buscar-se-á refletir sobre a verdade enquanto categoria filosófica. ${ }^{2}$

No texto que Gottlob Benjamin Jäsche estabeleceu com base nas lições públicas de Kant sobre Lógica, procurando reproduzi-las, Immanuel Kants Logik ein Handbuch zu Vorlesungen (Lógica de Immanuel Kant. Um Manual para Preleções, doravante Logik), a verdade é-nos apresentada como «uma das mais importantes perfeições do conhecimento e até mesmo a condição essencial e inseparável de toda a perfeição do mesmo» (KANT, 1992, Ak49). ${ }^{3}$ Um conhecimento precisa ser verdadeiro para que possa vir a ser considerado um conhecimento perfeito. ${ }^{4}$ Sobre a verdade acrescenta ainda que esta «consiste na concordância do conhecimento com o objeto.» (KANT, 1992, Ak50). ${ }^{5}$

Kant define a verdade como a concordância de um conhecimento com um ser objeto. A verdade é a conveniência do nosso conhecimento com o objeto, que é objeto desse mesmo conhecimento. ${ }^{6} \mathrm{Um}$ conhecimento

\footnotetext{
${ }^{2}$ Apenas uma nótula de esclarecimento conceptual: embora a presente investigação se desenvolva em torno do pensamento kantiano, não se utiliza aqui o termo "categoria" no sentido kantiano de um conceito puro a priori como conceito de síntese para a unificação do diverso; aqui toma-se "categoria" em sentido lato.

3 «Eine Hauptvollkommenheit des Erkenntnisses, ja die wesentliche und unzertrennliche Bedingung aller Vollkommenheit desselben, ist die Wahrheit.» (KANT, 1923, Ak49). Para todas as obras de Kant citadas ao longo do presente artigo, utilizam-se traduções portuguesas acompanhadas do respetivo texto original. As referências aqui presentes remetem para a edição crítica publicada pela Königlich Preussische Akademie der Wissenschaften (Kants Gesammelte Schriften).

${ }^{4} \mathrm{Um}$ conhecimento pode ser perfeito segundo as leis da sensibilidade, esta perfeição é estética, e ainda segundo as leis do entendimento e esta perfeição é lógica. (Cf. KANT, 1923, Einleitung, V).

5 «Wahrheit, sagt man, besteht in der Uebereinstimmung der Erkenntniss mit dem Gegenstande.» (KANT, 1923, Ak50).

${ }^{6}$ «Em termos de definição categorial, Kant encara a "verdade" (Wahrheit) - aparentemente dentro do paradigma clássico da "conveniência" - como "concordância" ou "adequação [...]" [...].» (BARATA-MOURA, 2007, p. 24). Tomás de Aquino é citado por BarataMoura a este propósito de modo a ilustrar o "paradigma clássico" da "conveniência" onde Kant se parece inserir: «Este nome verdadeiro exprime, deveras, a conveniência do ente ao intelecto» - «Convenientiam vero entis ad intellectum exprimit hoc nomen verum» (apud BARATA-MOURA, 2007, p. 24).
} 
verdadeiro será, pois, aquele que concorda com o seu objeto e a verdade é essa concordância. Assim, a verdade não é uma propriedade das coisas elas mesmas nem uma propriedade do entendimento ele mesmo considerado isoladamente. A verdade qualifica a relação de um objeto com o seu conhecimento, exprimindo que essa relação é uma conformidade. A par disto Kant adianta:

\begin{abstract}
Ora, só posso comparar o objeto com o meu conhecimento na medida em que o conheço. $\mathrm{O}$ meu conhecimento deve, pois, confirmar-se a si mesmo, o que, porém, nem de longe é suficiente para a verdade. Pois, visto que o objeto está fora de mim e o conhecimento está em mim, a única coisa que posso fazer é avaliar se o meu conhecimento do objeto concorda com o meu conhecimento do objeto. (KANT, 1992, Ak50). ${ }^{7}$
\end{abstract}

Kant afirma então que o conhecimento confirmar-se a si próprio não é suficiente para o considerar verdadeiro, parece necessário mas está longe de ser suficiente. Ainda assim, em tal necessidade parece haver um círculo, que o próprio autor admite e que se prende essencialmente com o facto de o sujeito não ter acesso àquilo que o objeto é fora de si. O sujeito que conhece apenas acede ao objeto enquanto fenómeno que, uma vez recebido, pela sensibilidade, o seu entendimento o permite pensar.

Mas se não consigo aceder ao objeto ele mesmo, como posso estabelecer e confirmar uma concordância do meu conhecimento com o objeto deste mesmo conhecimento? Kant chama a atenção para o facto de «a solução do problema em questão [ser], para qualquer um, absolutamente impossível» (KANT, 1992, Ak50) ${ }^{8}$ e converte a questão na pergunta pelo critério de verdade:

[...] o que se pergunta aqui é: se e em que medida haverá um critério da verdade seguro, universal e útil na aplicação. Pois é isto o que deve ser o sentido da questão: o que é a verdade? (KANT, 1992, Ak50). ${ }^{9}$

\footnotetext{
${ }^{7}$ «Nun kann ich aber das Object nur mit meinem Erkenntnisse vergleichen, dadurch, dass ich es erkenne. Meine Erkenntniss soll sich also selbst bestätigen, welches aber zur Wahrheit noch lange nicht hinreichend ist. Denn da das Object ausser mir und die Erkenntniss in mir ist, so kann ich immer doch nur beurtheilen: ob meine Erkenntniss vom Object mit meiner Erkenntniss vom Object übereinstimme.» (KANT, 1923, Ak50).

8 «Nur ist die Auflösung der gedachten Aufgabe schlechthin und für jeden Menschen unmöglich.» (KANT, 1923, Ak50).

9 «Es fragt sich nämlich hier: ob und inwiefern es ein sicheres, allgemeines und in der Anwendung brauchbares Kriterium der Wahrheit gebe? — Denn das soll die Frage: was ist Wahrheit? — bedeuten.» (KANT, 1923, Ak50).
} 
"O que torna um conhecimento verdadeiro?”, “o que nos permite distinguir o que é verdadeiro?”. Esta é, precisamente, a questão que, enquadrada no problema da verdade, mais preocupa o autor. Ele chega mesmo a considerar que a pergunta pela verdade devém na pergunta pelo critério de verdade. O problema essencial não é tanto a definição de verdade, mas, sim, o critério que nos permite afirmar que estamos no verdadeiro - qual o critério de verdade?

[...] Que é a verdade? - Kant responde - A definição nominal do que seja a verdade, que consiste na concordância do conhecimento com o seu objeto, admitimo-la e pressupomo-la aqui; pretende-se, porém, saber qual seja o critério geral e seguro da verdade de todo o conhecimento. (KANT, 1985, A58/B82). ${ }^{10}$

O problema da verdade centra-se nos critérios que nos permitem distinguir um conhecimento como verdadeiro.

Para poder decidir esta importante questão, é preciso com certeza distinguir aquilo que em nosso conhecimento pertence à matéria do mesmo e se relaciona com o objeto, daquilo que concerne à mera forma como a condição sem a qual um conhecimento não seria de todo um conhecimento. Por isso, com respeito a essa distinção entre o aspeto objetivo, material e o aspeto subjetivo, formal em nosso conhecimento, a questão acima divide-se nas duas questões particulares seguintes: 1) Será que há um critério material e universal da verdade? 2) Será que há um critério formal e universal da verdade? (KANT, 1992, Ak50). ${ }^{11}$

\footnotetext{
10 «[...] was ist Wahrheit? Die Nameuerklärung der Wahrheit, dass sie nämlich die Uebereinstimmung der Erkenntniss mit ihrem Gegenstande sei, wird hier geschenkt und vorausgesetzt; man verlangt aber zu wissen, welches das allgemeine und sichere riterium der Wahrheit einer jeden Erkenntniss sei.»(KANT, 1911, A58/B82). A tradução portuguesa é feita a partir da edição crítica de Raymund Schmidt, confrontada com a edição de Ernest Cassirer e com a edição publicada pela Königlich Preussische Akademie der Wissenschaften (Kants Gesammelte Schriften). As referências indicadas com "A" remetem para o texto da primeira edição e as referências indicadas com "B" remetem para o texto da segunda edição do texto original de Kant.

${ }^{11}$ «Um diese wichtige Frage entscheiden zu können, müssen wir das, was in unserem Erkenntnisse zur Materie desselben gehört und auf das Object sich bezieht, von dem, was die blose Form, als diejenige Bedingung betrifft, ohne welche ein Erkenntniss gar kein Erkenntuiss überhaupt sein würde, wohl unterscheiden. - Mit Eücksicht auf diesen Unterschied zwischen der objectiven, materialen und der subjectiven,formalen Beziehung in unserem Erkenntnisse, zerfällt daher die obige Frage in die zwei besonderen: 1) Gibt es ein allgemeines materiales, und 2) Gibt es ein allgemeines formales Kriterium der Wahrheit?»(KANT, 1923, Ak50).
} 


\section{A matéria e a forma do conhecimento}

Antes de mais investiguemos, ainda que sumariamente, como Kant distingue o que no conhecimento diz respeito à matéria deste daquilo que concerne à sua forma. O autor considera, como podemos ler acima, a matéria do conhecimento como o objeto de conhecimento, constituindo, pois, o aspeto objetivo do mesmo. "Resta" esclarecer o que se entende, dentro do seu pensamento, por objeto de conhecimento. Quanto à forma do conhecimento, procurar-se-á aqui explicitar como esta constitui o aspeto subjetivo do conhecimento e é condição sem a qual um conhecimento não pode ser de todo conhecimento (cf. KANT, 1923, Ak50).

Kant entende a matéria como o determinável, aquilo que é possível determinar; a forma é o que determina aquela matéria (cf. KANT, 1911, A266/B322). A forma ordena a matéria. Na sua teoria explicativa do conhecimento, o entendimento produz conhecimento se, e somente se, aplicado aos conteúdos fornecidos pela sensibilidade. Estes conteúdos são a matéria do conhecimento, o objeto [der Gegenstand] (cf. KANT, 1923, A34). Neste sentido se enquadra a afirmação de que conhecer é, para este mesmo autor, dar forma a uma matéria dada - é enformar a matéria -, sendo a forma o modo como conhecemos o objeto [die Art, wie wir den Gegenstand erkennen] (cf. KANT, 1923, A34). ${ }^{12}$

O conhecimento é, pois, constituído pela matéria e pela elaboração que esta sofre devido à estrutura do sujeito na qual se encontra o modo como conhecemos algo. É desta estrutura do sujeito que a forma do conhecimento faz parte, daí esta revelar o aspeto subjetivo deste último. A matéria provém da existência das coisas exteriores a nós ${ }^{13}$, que se "encontram" na experiência. A experiência, sendo ela própria «uma ligação

\footnotetext{
${ }^{12}$ Kant apresenta-se, no seu período crítico, numa luta contra o racionalismo dogmático e contra o empirismo, reconhecendo que nem a razão pode conhecer tudo por si mesma negligenciando os seus próprios limites, nem que o conhecimento. (Para uma síntese desta "dupla luta" veja-se: DELEUZE, 2000, pp.9-11.) Kant propõe-se a delimitar o alcance da razão no conhecimento teórico e é atendendo a essas limitações que considera que não bastam as formas para constituir um conhecimento, tem de haver um objeto que afete as formas da sensibilidade, que seja objeto do conhecimento.

${ }^{13}$ Mesmo que não as conheçamos em si mesmas, pois não alcançamos a coisa em si (Ding an sich), são as coisas exteriores a nós que nos afetam os sentidos e é à sua aparição (Erscheinung) neles que acedemos, recebendo-a nas formas da sensibilidade que permitem a ordenação do diverso dessa mesma aparição (cf. KANT, 1911, A20/B34). A sensação é aqui a matéria da sensibilidade. Importa não confundir matéria e forma da sensibilidade com matéria e forma do conhecimento. A sensibilidade tem o seu conteúdo (matéria) e as suas formas, que apenas se assemelham à matéria e forma do conhecimento na medida em que abstraímos toda a diferença entre o que é dado como determinável e o modo como esse mesmo dado é determinado, sendo, então, toda a matéria o que é determinável e toda a forma o que a determina.
} 
sintética das intuições» (KANT, 1985, B12) $)^{14}$, apresenta-se como fornecedora da matéria a que os conceitos do entendimento se podem aplicar (cf. KANT, 1911, A63/B87-88).

Todo o conhecimento é constituído numa relação entre a sua matéria, que é o objeto de conhecimento, e a sua forma que se encontra na própria estrutura do sujeito, não sendo dada pela experiência e que, como tal, é a priori. Temos então a forma do conhecimento que é a priori e temos a matéria que, de acordo com tudo o que até agora foi referido, é a posteriori. Significa isto que não há, então, objeto de conhecimento a priori e que, portanto, toda a matéria do conhecimento é a posteriori?

Kant distinguiu dois tipos de juízos: analíticos e sintéticos. Os primeiros nada acrescentam ao conceito - o predicado já se encontra contido no sujeito; os segundos acrescentam um predicado ao conceito de sujeito que não estava já neste pensado nem dele podia ser extraído por qualquer decomposição (cf. KANT, 1911, A6 ss./B10 ss.; KANT, 1911', A25). ${ }^{15}$

$\mathrm{Na}$ medida em que apenas os juízos sintéticos acrescentam informação sobre o sujeito, Kant considerará que apenas estes representam um conhecimento significativo na medida em que é extensivo e não meramente explicativo (cf. KANT, 1911, A10/B13-14). Para o autor o conhecimento é mais do que uma análise e decomposição de conceitos. Mas isto não significa que todo o conhecimento é a posteriori.

É certo que todos os juízos analíticos são a priori, mas os juízos sintéticos não são todos a posteriori. Segundo o autor, há juízos sintéticos a priori e juízos sintéticos a posteriori. Infere-se daqui que há conhecimento $a$ posteriori mas também a priori.

Considerando que a intuição pura (reine Anschauung), é a intuição a priori e a intuição sensível (sinnliche Anschauunh), a posteriori e como todo o conhecimento tem um conteúdo, pois sem este temos um "conhecimento" vazio, que efetivamente não será conhecimento: a matéria do conhecimento a priori é a intuição pura, enquanto a matéria do conhecimento a posteriori é a intuição sensível.

Atente-se ainda que esta materialidade que a objetividade kantiana significa, uma vez enquadrada na problemática da verdade, não é «a materialidade ontológica de uma existência determinadamente autofundada, - como nos diz Barata-Moura - mas a "materialidade" constituída - na e por uma consciência - de um conteúdo que se não deixa reconduzir integral e exclusivamente ao "complexo" (Inbegriff) dos elementos formais abstratos.» (BARATA-MOURA, 2007, p. 24). O conhecimento não é constituído pela mera forma abstrato, tem de haver uma matéria suscetível

\footnotetext{
14 «Erfahrung, die selbst eine synthetische Verbindung der Anschauungen ist» (KANT, 1911, B12).

15 A presente referência de Prolegomena zu einer jeden kün ftigen Metaphysik die als Wissenschaft wird auftreten können (doravante: Prolegomena) remete para a página da edição alemã original de 1783.
} 
de poder ser enformada para que te tenha, então, um conhecimento. Sem uma matéria do conhecimento este não tem conteúdo, não há, pois, um objeto de conhecimento, mas somente "conhecimento" vazio.

Pode-se, nesse caso, considerar possível afirmar que não se conhece "nada", pois o que preenche este "nada" é essa mesma matéria. Por outro lado, não basta ter um conteúdo, é preciso determiná-lo para que se possa afirmar que se conhece, que há conhecimento. Esta determinação dá-se pela forma. Se como se afirmou conhecer é um enformar da matéria, sendo que a forma ordena, regula, esta, então se percebe que a forma é a tal condição sem a qual o conhecimento não é conhecimento. O objeto do conhecimento encontra-se, assim, submetido às formas do sujeito para este o poder conhecer.

\section{A verdade material e a verdade formal}

Uma vez entendendo o que respeita à matéria do conhecimento e à forma deste, Kant parece falar sobre uma verdade material (objectiva) materielle (objektive) Wahrheit) - e uma verdade formal - formale Wahrheit -, distinção sobre a qual nos debruçaremos agora, movidos pelas duas questões acima colocadas, não esquecendo que a pergunta pela verdade deve ser, segundo Kant, entendida como a pergunta pelo critério de verdade: «1) Será que há um critério material e universal da verdade? 2) Será que há um critério formal e universal da verdade?» (KANT, 1992, Ak50).

Busca-se definir um critério de verdade que seja universal e não particular, o que significa que deverá ser um critério válido para todos os casos, para todos os objetos em geral, abstraindo toda e qualquer particularidade e a distinção entre estas. A questão que se coloca é se existe um tal critério material e/ou formal.

\section{Sobre a possibilidade de um critério material e universal de verdade}

Na Logik, Kant adianta logo, diretamente e sem rodeios, que «um critério material e universal da verdade não é possível; tal coisa é até mesmo autocontraditória.» (KANT, 1992, Ak50). ${ }^{17}$ E explica porque será autocontraditório considerar a possibilidade de estabelecer um critério material e universal de verdade:

Pois, enquanto um critério universal, válido para todos os objetos em geral, ele teria que abstrair completamente de toda

\footnotetext{
16 «1) Gibt es ein allgemeines materiales, und

2) Gibt es ein allgemeines formales Kriterium der Wahrheit?» (KANT, 1923, Ak50).

17 «Ein allgemeines materiales Kriterium der Wahrheit ist nicht möglich; - es ist sogar in sich selbst widersprechend.» (KANT, 1923, Ak50).
} 
distinção entre os objetos, e no entanto, enquanto critério material, também teria ao mesmo tempo de visar exatamente essa distinção, para poder determinar se um conhecimento concorda precisamente com o objeto ao qual se relaciona, e não com um objeto qualquer em geral - o que, a rigor, não quer dizer nada. (KANT, 1992, Ak50-51). ${ }^{18}$

Já em Kritik der reinen Vernunft Kant havia explicado porque seria impossível um critério material e universal de verdade que fosse válido para todos os conhecimentos, sem distinção dos seus objetos (cf. KANT, 1911, A58-59/B83). Um critério material dirá sempre respeito a um determinado objeto, terá sempre que permitir distinguir um determinado objeto de todos os outros, não se podendo abstrair das diferenças, pois são estas que revelam a manifestação concreta das determinações dos objetos. Só assim se poderá alcançar a verdade material que consiste «nessa concordância do conhecimento com o objeto determinado ao qual se relaciona» (KANT, 1992, Ak51) ${ }^{19}$, o que não se coaduna com a possibilidade de se tornar num critério universal.

Ora, o facto de não haver um critério material e universal de verdade não significa que não haja uma verdade material, simplesmente não há um critério universal que nos permita distinguir, materialmente, por referência ao objeto de conhecimento, que estamos na posse de um conhecimento verdadeiro. Na esteira do que o autor afirma:

Pois um conhecimento que é verdadeiro com relação a um objeto, pode ser falso com respeito a outros objetos. Por isso, é absurdo exigir um critério material e universal da verdade, devendo ao mesmo tempo abstrair e não abstrair de toda distinção entre os objetos. (KANT, 1992, Ak51). ${ }^{20}$

A verdade material não é negada por Kant, sendo mesmo necessária na sua conceção de verdade, como enunciado. Contanto, não se esqueça que esta materialidade da verdade, que devém na sua dimensão objetiva, no

\footnotetext{
18 «Denn als ein allgemeines,für alle Objecte überhaupt gültiges, müsste es von allem Unterschiede derselben völlig abstrahiren und doch auch zugleich als ein materiales Kriterium eben auf diesen Unterschied gehen, um bestimmen zu können, ob ein Erkenntniss gerade mit demjenigen Objecte, worauf es bezogen wird, und nicht mit irgend einem Object überhaupt, — womit eigentlich gar nichts gesagt wäre, — übereinstimme.», (KANT, 1923, Ak50-51).

19 «In dieser Uebereinstimmung einer Erkenntniss mit demjenigen bestimmten Objecte, worauf sie bezogen wird, muss aber die materiale Wahrheit bestehen.» (KANT, 1923, Ak$51)$.

${ }^{20}$ «Denn ein Erkenntniss, welches in Ansehung eines Objectes wahr ist, kann in Beziehung auf andere Objecte falsch sein. Es ist daher ungereimt, ein allgemeines materiales Kriterium der Wahrheit zu fordern, das von allem Unterschiede der Objecte zugleich abstrahiren und auch nicht abstrahiren solle.» (KANT, 1923, Ak51).
} 
sentido crítico kantiano, revela-se numa constituição transcendental, considerando que o objeto é, para Kant, transcendentalmente constituído.

Não sendo possível um critério material e universal de verdade, coloca-se então a questão sobre que tipo de critério de verdade, que seja universal, é possível.

\section{Sobre a possibilidade de um critério formal e universal de verdade}

Por "oposição" a uma verdade material, que considera o conteúdo do conhecimento, o seu objeto, e é, portanto, objetiva, afirma-se uma verdade formal. Esta atém-se somente às leis gerais do entendimento e da razão e, como tal, Kant apresenta-a como consistindo «unicamente na concordância do conhecimento consigo próprio, abstração feita de todos os objetos e de toda distinção entre os mesmos.» (KANT, 1992, Ak51). ${ }^{21}$ Trata-se de uma verdade lógica sobre a qual é possível estabelecer critérios formais e universais de verdade uma vez que:

No que respeita, porém, ao conhecimento, considerado simplesmente segundo a mera forma (pondo de parte todo o conteúdo), é igualmente claro que uma lógica, na medida em que expõe as regras gerais e necessárias do entendimento, deverá nessas mesmas regras expor critérios de verdade. (KANT, 1985, A59/B83-84). ${ }^{22}$

Neste sentido, o autor afirma que:

Os critérios formais e universais da verdade nada mais são, por conseguinte, do que as características lógicas universais da concordância do conhecimento consigo próprio, ou - o que dá no mesmo - com as leis universais do entendimento e da razão. $(\mathrm{KANT}, 1992, \mathrm{Ak} 51){ }^{23}$

21 «Denn die formale Wahrheit besteht lediglich in der Zusammenstimmung der Erkenntniss mit sich selbst bei gänzlicher Abstraction von allen Objecten insgesammt und von allem Unterschiede derselben.» (KANT, 1923, Ak51).

22 «Was aber das Erkenntniss der blosen Form nach (mit Beiseitesetzung alles Inhalts) betrifft, so ist eben so klar, dass eine Logik, so fern sie die allgemeinen und nothwendigen Regeln des Verstandes vorträgt, eben in diesen Regeln Kriterien der Wahrheit darlegen müsse.» (KANT, 1911, A59/B83-84).

${ }_{23}$ «Und die allgemeinen formalen Kriterien der Wahrheit sind demnach nichts Anderes, als allgemeine logische Merkmale der Uebereinstimmung der Erkenntniss mit sich selbst oder, — welches einerlei ist, — mit den allgemeinen Gesetzen des Verstandes und der Vernunft.», (KANT, 1923, Ak51). 
A verdade formal surge como uma verdade lógica. A própria lógica trata da questão de o conhecimento se conhecer a si mesmo ${ }^{24}$, sendo a «ciência das leis necessárias do entendimento e da razão em geral, ou - o que dá no mesmo - da mera forma do pensamento em geral» (KANT, 1992, Ak13) ${ }^{25}$. A lógica, assim entendida, terá ela mesma as características da concordância do conhecimento consigo próprio e esta concordância é a verdade formal. Encontraremos, então, na lógica, os critérios formais da verdade que poderão ser universais uma vez sendo possível abstrair de todas as diferenças entre os objetos, pois aqui atenderemos somente à forma.

Kant apresenta o princípio de não-contradição como o critério universal de toda a verdade, sendo o critério elementar e necessário desta:

Ora a proposição: A coisa alguma convém um predicado que a contradiga, denomina-se princípio de contradição e é um critério universal, embora apenas negativo, de toda a verdade. $(\text { KANT, 1985, A151/B190) })^{26}$

Este princípio fixa a possibilidade lógica de um conhecimento. Daqui se segue, pois, que um conhecimento para ser verdadeiro tem que ser logicamente possível, isto é, não convém que se contradiga (cf. KANT, 1923, Ak51). A razão pela qual se trata de um critério negativo será assunto sobre o qual nos debruçaremos de seguida.

A verdade é apresentada como uma perfeição do conhecimento segundo a relação, pois diz-se sobre a relação do meu conhecimento, neste caso, sendo lógica, consigo mesmo (cf. KANT, 1923, Einleitung, VII). Importa especificar a parte da lógica que nos pode servir, segundo Kant, como "pedra de toque", nem que seja simplesmente negativa, da verdade, uma vez que o próprio autor divide a tarefa da lógica geral em analítica e dialética (cf. KANT, 1911, transzendentale Logik, Einleitung, III).

A parte da lógica que nos pode servir como "pedra de toque", pelo menos negativa, para a verdade é a parte analítica. Esta restringe-se às formas do pensamento em geral e servir-nos-á «na medida em que, primeiramente, comprovar e avaliar com base nestas regras, todo o conhecimento, quanto à sua forma, antes de investigar o seu conteúdo para

\footnotetext{
${ }^{24}$ «Na Lógica trata-se apenas da questão: como é que o conhecimento há de se conhecer a si mesmo?»(KANT, 1992, Ak14) - «In der Logik ist nur die Frage: wie wird sich der Verstand selbst erkennen?» (KANT, 1923, Ak14).

25 «Diese Wissenschaft von den notwendigen Gesetzen des Verstandes und der Vernunft überhaupt oder, welches einerlei ist, von der blosen Form des Denkens überhaupt, nennen wir nun Logik.» (KANT, 1923, Ak13).

${ }^{26}$ «Der Satz nun : keinem Dinge kommt ein Prädicat zu, welches ihm widerspricht, heisst der Satz des Widerspruchs, und ist ein allgemeines, obzwar blos negatives Kriterium aller Wahrheit» (KANT, 1911, A151/B190).
} 
descobrir se em relação ao objeto contém uma verdade positiva.» (KANT, 1985, A60/B84-85). ${ }^{27}$

Contudo, sobre esse conteúdo a lógica não se poderá pronunciar, uma vez que se atém simplesmente às formas do pensamento em geral. Daí servir como "pedra de toque" negativa, pois apresenta-nos as condições necessárias para a distinção da verdade, mas tais condições não são suficientes. Ao julgar-se que, para além de necessárias, são também suficientes, está a julgar-se que se pode conhecer somente pensando e aí caise numa lógica da aparência, sobre a qual se falará adiante, que é a parte dialética da lógica (cf. KANT, 1911, A60-61/B85-86).

Nesta analítica temos então uma "doutrina" da verdade formal. ${ }^{28}$ Kant referia que antes de verificar se o conhecimento concorda com o objeto, teria de se questionar se o conhecimento concordaria consigo próprio, isto segundo a forma, e esta tarefa cabe, então, à lógica. Um conhecimento que não se considere possível, pelas características lógicas universais de concordância de um conhecimento consigo próprio, não é um conhecimento verdadeiro na medida em que a contradição o destrói.

Encontramos então um critério universal de verdade: um conhecimento para ser verdadeiro não se pode contradizer a si mesmo - tem de concordar consigo mesmo. Mas este é um critério formal que «pertence unicamente à lógica, porque vale só para conhecimentos considerados simplesmente como conhecimentos em geral, independentemente do seu conteúdo, e afirma que a contradição os destrói totalmente» (KANT, 1985, A151/B190). ${ }^{29}$

Temos um critério formal e universal de verdade, mas não há um critério material e universal de verdade. Aquele não é, no entanto, suficiente para estabelecer a verdade porque esta não deixa de ser a concordância do conhecimento com o seu objeto, tendo uma dimensão material.

\footnotetext{
${ }^{27}$ «Dieser Theil der Logik kann daher Analytik heissen und ist eben darum der wenigstens negative Probierstein der Wahrheit, indem man zuvörderst alle Erkenntniss, ihrer Form nach, an diesen Regeln prüfen und schätzen muss, ehe man sie selbst ihrem Inhalt nach untersucht, um auszumachen, ob sie in Ansehung des Gegenstandes positive Wahrheit enthalten.» (KANT, 1911, A60/B84-85).

${ }^{28}$ Nos Prolegomena, o autor, num dos seus esclarecimentos sobre a noção Analitik, escrevia: «O nome de analítica designa também uma parte principal da lógica e é então a lógica da verdade, por oposição à dialética, sem que verdadeiramente se considere que os conhecimentos a ela pertencentes sejam analíticos ou sintéticos.» (KANT, 1988, A42) «Noch kommt der Name Analytik auch als ein Haupttheil der Logik vor, und da ist es die Logik der Wahrheit, und wird der Dialektik entgegengesetzt, ohne eigentlich darauf zu sehen, ob die zu jener gehörigen Erkenntnisse analytisch oder synthetisch seien.» (KANT, 1911', A42).

${ }^{29}$ «der Satz des Widerspruchs [...] gehört aber auch darum blos in die Logik, weil er von Erkenntnissen, blos als Erkenntnissen überhaupt, unangesehen ihres Inhalts gilt und sagt : dass der Widerspruch sie gänzlich vernichte und aufhebe.» (KANT, 1911, A151/B190).
} 


\title{
O critério formal de verdade não garante verdade material (objetiva)
}

Quando Kant refere que o princípio de não-contradição é o critério universal de toda a verdade em sentido negativo (cf. KANT, 1911, A151/B190), refere-se ao facto de que um tal princípio, enquanto critério meramente formal, não pode ser capaz de garantir a verdade material (objetiva) - die materielle (objektive) Wahrheit. Um critério formal não se pode aplicar à matéria do conhecimento, mas apenas à forma deste.

Encontramos a "pedra de toque" da verdade mas em sentido negativo, pois temos apenas o critério necessário de verdade mas não suficiente:

\begin{abstract}
Estes critérios [formais] referem-se, todavia, apenas à forma da verdade, isto é, do pensamento em geral e, como tais, são certos, mas não suficientes. Porque, embora um conhecimento seja perfeitamente adequado à forma lógica, isto é, não se contradiga a si próprio, pode todavia estar em contradição com o objeto. Assim, o critério puramente lógico da verdade, ou seja, a concordância de um conhecimento com as leis gerais e formais do entendimento e da razão, é uma conditio sine qua non, por conseguinte a condição negativa de toda a verdade. (KANT, 1985, A59-60/B84). ${ }^{30}$
\end{abstract}

O critério formal e universal de verdade dá-nos a condição sem a qual não distinguimos o verdadeiro, mas ainda assim não nos permite afirmar que um conhecimento é verdadeiro, apenas que é possível (logicamente) que o seja. A simples correção formal do conhecimento é insuficiente para nos dar a verdade material dos objetos de conhecimento (cf. KANT, 1911, A60/B85).

Kant declara que um tal critério formal é necessário e suficiente para todo o conhecimento analítico. Neste sentido, um tal critério não tem um uso meramente negativo, mas positivo na medida em que nos permite reconhecer a verdade:

Porque, se um juízo é analítico, quer seja negativo ou afirmativo, a sua verdade deverá sempre poder ser suficientemente reconhecida pelo princípio de contradição. [...] Temos portanto que admitir que o princípio de

\footnotetext{
30 «Diese Kriterien aber betreffen mir die Form der Wahrheit, d. i. des Denkens überhaupt, und sind so fern ganz richtig, aber nicht hinreichend. Denn obgleich eine Erkenntniss der logischen Form völlig gemäss sein möchte, d. i. sich selbst nicht widerspräche, so kann sie doch noch immer dem Gegenstände widersprechen. Also ist das blos logische Kriterium der Wahrheit, nämlich die Uebereinstimmung einer Erkenntniss mit den allgemeinen und formalen Gesetzen des Verstandes und der Vernunft zwar die conditio sine qua non, mithin die negative Bedingung aller Wahrheit» (KANT, 1911, A59-60/B84).
} 
contradição é o princípio universal e plenamente suficiente de todo o conhecimento analítico. (KANT, 1985, A151/B190). ${ }^{31}$

Isto porque o conhecimento analítico, sendo um juízo analítico ${ }^{32}$, é aquele em que o objeto do conhecimento se encontra já pensado no próprio conceito, abstraindo de toda a experiência. Assim, o juízo analítico apenas tem de concordar consigo próprio, basta que não se contradiga de acordo com as leis do entendimento (cf. KANT, 1911, A 150/B 189; KANT, 1911', A25).

Mas tratando da parte sintética do nosso conhecimento, algo mais é exigido:

Os juízos sintéticos exigem um princípio diferente do princípio de contradição: Há juízos sintéticos a posteriori, cuja origem é empírica; mas também os há que são certos a priori e proveem do puro entendimento e da razão. Uns e outros concordam em que eles nunca podem existir em virtude do axioma fundamental da análise, isto é, do simples princípio de contradição; exigem ainda um princípio inteiramente diferente, embora sempre devam ser derivados de todo o princípio, seja ele qual for, em conformidade com o princípio de contradição; nada, pois, se deve opor a este princípio, embora nem tudo dele possa ser derivado. (KANT, 1911', A26-27). ${ }^{33}$

$\mathrm{O}$ conhecimento tem de respeitar o princípio de não-contradição, mas não podemos derivar todos os critérios de verdade deste mesmo princípio. Se assim o fizéssemos culminaríamos numa teoria de verdade segundo uma coerência interna o que é de todo insuficiente. Efetivamente a

\footnotetext{
31 «Denn wenn das Urtheil analytisch ist, es mag nun verneinend oder bejahend sein, so muss dessen Wahrheit jederzeit nach dem Satze des Widerspruchs hinreichend können erkannt werden.[...] Daher müssen wir auch den Satz des Widerspruchs als das allgemeine und völlig hinreichende Principium aller analytischen Erkenntniss gelten lassen» (KANT, 1911, A151/B190).

${ }^{32} \mathrm{O}$ conhecimento é entendido como um juízo. Uma conceção que se poderá considerar simplista dentro do pensamento kantiano, mas que não se afasta dele. Kantianamente, entende-se aqui o juízo enquanto relação do objeto, na medida em que é intuído, com o nosso entendimento (cf. KANT, 1911, A293/B350).

33 «Synthetische Urtheile bedürfen ein anderes Princip, als den Satz des Widerspruchs. Es gibt synthetische Urtheile a posteriori, deren Ursprung empirisch ist; aber es gibt auch deren, die a priori gewiss sind und die aus reinem Verstände und Vernunft entspringen. Beide kommen aber darin überein, dass sie nach dem Grundsatze der Analysis, nämlich dem Satze des Widerspruchs allein nimmermehr entspringen können; sie erfordern noch ein ganz anderes Princip, ob sie zwar aus jedem Grundsatze, welcher er auch sei, jederzeit dem Satze des Widerspruchs gemäss abgeleitet werden müssen, denn nichts darf diesem Grundsatze zuwider sein , obgleich eben nicht alles daraus abgeleitet werden kann.» (KANT, 1911', A26-27).
} 
verdade não brota da mera forma. A verdade formal garante a validade do conhecimento, mas a validade não garante a verdade.

A lógica, portanto, enquanto cânone do pensamento, diz quais são as regras formais do uso do entendimento, mas nada diz sobre a verdade. Mas esta lógica é a lógica geral (allgemeine Logik), como Kant lhe chama, que é uma lógica abstrata, formal, que deixa de parte toda e qualquer referência ao objeto, focando-se unicamente na forma do pensar. Deste modo, tal lógica fica excluída de se pronunciar sobre a materialidade da verdade, nada nos pode dizer sobre a verdade objetiva pois restringe-se ao aspeto subjetivo da verdade.

O próprio Kant declarou que seria preciso ir além da lógica formal e esse ir além desta é passar a uma lógica transcendental (transzendentale Logik). Esta, sem invalidar aquela, será uma ciência capaz de determinar a origem, o âmbito e o valor objetivo dos conhecimentos (cf. KANT, 1911, A57/B81). Ela é uma ciência do entendimento puro e do conhecimento de razão pela qual pensamos objetos absolutamente $a$ priori.

Também a lógica transcendental, assim como a lógica geral, se divide numa parte analítica e numa parte dialética. Aquela, que é a que nos interessa agora, apresenta-nos os elementos do conhecimento puro do entendimento e os princípios que nos permitem pensar um objeto e, por conseguinte, sem os quais nenhum objeto pode ser pensado (cf. KANT, 1911,A62/B87).

A analítica transcendental (transzendentale Analitik) é apresentada como uma lógica da verdade (Logik der Wahrheit) na medida em que «nenhum conhecimento pode contradizê-la sem que perca, ao mesmo tempo, todo o conteúdo, isto é, toda a relação a qualquer objeto e, portanto, toda a verdade.» (KANT, 1985, A62-63/B87). ${ }^{34}$ Se se perde toda a relação ao conteúdo do conhecimento, acaba por se perder toda a verdade pois esta encontra-se precisamente na relação do nosso conhecimento com o seu objeto, que é o seu conteúdo. Não é possível estabelecer uma concordância com o vazio pois nem sequer é possível estabelecer uma relação com algo que não está presente.

Se a lógica geral abstrai todo o conteúdo do conhecimento, a lógica transcendental «defronta-se com o diverso da sensibilidade a priori, que a estética transcendental lhe fornece, para dar uma matéria aos conceitos puros do entendimento, sem a qual esta lógica seria destituída de conteúdo, portanto, completamente vazia.» (KANT, 1985, A76/B102). ${ }^{35}$ Temos,

\footnotetext{
${ }^{34}$ «Denn ihr kann keine Erkenntniss widersprechen,ohne dass sie zugleich allen Inhalt verlöre, d. i. alle Beziehung auf irgend ein Object, mithin alle Wahrheit.» (KANT, 1911, A62-63/B87).

35 «die transzcendentale Logik ein Mannigfaltiges der Sinnlichkeit a priori vor sich liegen, welches die transzcendentale Äesthetik ihr darbietet, um zu den reinen Verstandesbegriffen einen Stoff zu geben, ohne den sie ohne allen Inhalt, mithin völlig leer sein würde.» (KANT, 1911, A76/B102). Tornando-se o espaço que nos está reservado exíguo para
} 
portanto, a relação ao objeto assegurada. Estaremos então em condições de estabelecer critérios universais de verdade que nos garantam absolutamente a própria verdade enquanto concordância do nosso conhecimento com o seu objeto?

Na realidade a lógica transcendental não resolve por si o problema, pois esta apenas pretenderá determinar os modos de consciência de um objeto em geral, pensando assim a constituição transcendental de objetos em geral, e não chega a efetivar o objeto.

Como nos diz Barata-Moura: «A lógica geral pode fornecer as normas formais genéricas da verdade, a lógica transcendental pode esclarecer a constituição do objeto, mas a verdade material não dispensa a efetiva evidenciação deste.» (BARATA-MOURA, 2007, p. 25). É neste sentido e por isto que Kant declara que no juízo sintético em si mesmo não podemos conhecer a verdade nem o erro (cf. KANT, 1911, A154155/B193-194). Não basta comparar o juízo a si mesmo e procurar a verdade nessa comparação em que se relaciona apenas o juízo a si mesmo (a menos, claro está, que se trate de um juízo analítico).

\section{Nótulas conclusivas: a verdade e o erro}

O erro, segundo Kant, é a falsidade tomada por verdade. A falsidade é o contrário da verdade (cf. KANT, 1923, Ak53). Embora, como acima se disse, não se conheça a verdade e o erro no juízo (sintético) em si mesmo, tanto aquela como aquele apenas têm lugar precisamente no juízo. Um juízo pode ser verdadeiro ou falso e um juízo falso poderá ser um juízo erróneo na medida em que, sendo falso é tomado como verdadeiro.

O valor de verdade é sobre a cópula que liga um "sujeito" a um "predicado". Será desejado que tal cópula represente uma conveniência de um conhecimento com o seu objeto para que se possa afirmar que um certo juízo é verdadeiro. A verdade encontra-se numa ligação predicativa adequada.

Uma ligação predicativa apenas tem lugar no juízo e, portanto, a verdade apenas se pode dizer de um juízo (cf. KANT, 1923, Ak53), na medida em que este traduz uma relação do objeto com o nosso entendimento, um juízo que, enquanto conhecimento, é mais que mero pensar, é um pensar que liga, numa consciência, representações intuídas (cf. KANT, 1911', A88).

um maior aprofundamento na distinção entre a lógica geral (formal) e a lógica transcendental sugere-se a consulta de L'œeuvre de Kant - La philosophie critique, Tomo I, de Alexis Philonenko (2003, pp.111-113); e, mais especificamente acerca da lógica transcendental, sugere-se, por exemplo, o estudo desenvolvido, em língua portuguesa, por Pedro Alves, «O conceito de uma Lógica Transcendental» (2009, pp.11-20). 
A verdade não é, portanto, mero produto da ação isolada do entendimento, mas conta com o contributo das outras faculdades para o seu estabelecimento.

A verdade diz-se sobre a relação do conhecimento com o seu objeto e tal relação deve ser de concordância. Se uma tal concordância não ocorre, então não temos um conhecimento verdadeiro. Um conhecimento para ser verdadeiro, vimos já, tem de concordar consigo mesmo, não se pode contradizer sob pena de se autodestruir. Mas ainda assim, um conhecimento que não se contradiga pode não concordar com o objeto a que se refere, ligando conceitos de um modo que o objeto não comporta ou sem ter um fundamento (a priori ou a posteriori) que justifique um tal juízo e aí temos um conhecimento falso ou infundado (cf. KANT, 1911, A150/B189-190).

$\mathrm{O}$ princípio de não contradição tem, como atrás se referiu, um uso positivo, a saber, o de nos permitir reconhecer a verdade. Mas, para além deste, Kant havia enunciado um outro uso positivo que é a possibilidade de banir a falsidade e o erro na medida em que estes assentam na contradição (cf. KANT, 1911, A151/B190). Mas isto passa-se a um nível formal e, portanto, tais usos positivos aplicam-se aos juízos analíticos.

Kant diz-nos que é a aparência que induz ao erro (cf. KANT, 1911, A293/B350; KANT, 1923, Ak54). Aqui importa distinguir aparência (Schein) de aparição (fenómeno - Erscheinung). O objeto da intuição é o objeto que aparece (não que parece) à sensibilidade. Esta é a capacidade da mente de ser afetada pelo real produzindo intuições que doam algo e este algo é Erscheinung (cf. KANT, 1911, transzendentale Ästhetik, §1). Este não é, pois, o objeto real em si, não é coisa em si (Ding na sich). Schein é ilusão e Erscheinung não é uma ilusão.

Intuindo um objeto e pensando sobre ele de acordo com as leis do entendimento, não há, à partida, como errar. Contudo, quando a sensibilidade age sobre o entendimento (quando na verdade deveria ser o oposto), gera-se a perceção de uma aparência que tomamos por verdade e aî temos o erro (cf. KANT, 1923, Ak53). Este, tal como a verdade, não está, todavia, e note-se, na sensibilidade considerada isoladamente, nem no entendimento e nas suas leis (cf. KANT, 1923, Ak53; KANT, 1911, A293294/B350-351; KANT, 1911', A65-66).

A fonte de todo o erro terá de ser procurada única e exclusivamente na influência desapercebida da sensibilidade sobre o entendimento, ou, para falar mais exatamente, sobre o juízo. (KANT, 1992, Ak53-54). ${ }^{36}$

\footnotetext{
${ }^{36}$ «Der Entstehungsgrund alles Irrthums wird daher einzig und allein in dem unvermerkten Einflüsse der Sinnlichkeit auf den Verstand, oder genauer zu reden, auf das Urtheil, gesucht werden müssen.» (KANT, 1923, Ak53-54); cf. KANT, 1911, A294/B350-351.
} 
É essa influência que nos leva a tomar a aparência por verdade e é a aparência que torna o erro possível, tomando as razões subjetivas como objetivas, confundindo-as. É como se o entendimento se se distraísse deixando a sensibilidade desempenhar um papel que não é seu.

\begin{abstract}
Da natureza do erro, cujo conceito encerra, como observamos, além da falsidade, ainda aparência da verdade a título de característica essencial, resulta para a verdade de nosso conhecimento a seguinte e importante regra: A fim de evitar erros - e inevitável nenhum erro o é absoluta ou simplesmente, muito embora o possa ser relativamente para os casos em que, mesmo sob o risco de errar, é inevitável para nós julgar repetindo, a fim de evitar erros, é preciso procurar descobrir explicar a fonte dos mesmos, a aparência. (KANT, 1992, Ak55-56). ${ }^{37}$
\end{abstract}

O filósofo de Königsberg fala-nos de uma lógica da aparência (eine Logik des Scheins), a parte dialética da lógica, em que se utiliza a lógica além dos seus limites para o conhecimento, julgando que se pode conhecer simplesmente pensando. Mais do que um cânone do pensamento, a lógica é aí julgada como órganon julgando-se que as leis lógicas são condição necessária e suficiente para a verdade. Caímos, então, numa aparência ilusória que mais não é que fonte de erros e nos lança à falsidade, não à verdade.

Em suma, na investigação sobre a verdade não podemos descurar que o conhecimento é o enformar da matéria e que, portanto, a verdade se constitui formal e materialmente, subjetiva e objetivamente. Se nos atendermos apenas a um dos aspetos votamo-nos ao erro, pelo qual vislumbramos apenas a falsidade.

\title{
Referências bibliográficas
}

\section{Bliografia principal:}

KANT, Immanuel. Kritik der reinen Vernunft; Kants Gesammelte Schriften, Königlich Preussische Akademie der Wissenschaften. Berlin: Druck und Verlag von Georg Reimer, 1911, vol. III.

\footnotetext{
${ }^{37}$ «Aus der Natur des Irrthums, in dessen Begriffe, wie wir bemerkten, ausser der Falschheit, noch der Schein der Wahrheit als ein wesentliches Merkmal enthalten ist, ergibt sich für die Wahrheit unseres Erkenntnisses folgende wichtige Regel: Um Irrthümer zu vermeiden, - und unvermeidlich ist wenigstens absolut oder schlechthin kein Irrthum, ob er es gleich beziehungsweise sein kann für die Fälle, da es, selbst auf die Gefahr zu irren, unvermeidlich für uns ist, zu urtheilen, - also um Irrthümer zuvermeiden, muss man die Quelle derselben, den Schein, zu entdecken und zu erklären suchen.» (KANT, 1923, Ak5556).
} 
Prolegomena zu einer jeden kün ftigen Metaphysik die

als Wissenschaft wird auftreten können; Kants Gesammelte Schriften, Königlich Preussische Akademie der Wissenschaften. Berlin: Druck und Verlag von Georg Reimer, 1911', vol. IV.

Logik ein Handbuch zu Vorlesungen; Kants Gesammelte

Schriften, Königlich Preussische Akademie der Wissenschaften. Berlin und Leipzig: W. de Gruyter \& Co., 1923, vol. IX.

\section{Traduções utilizadas:}

KANT, Immanuel. Crítica da Razão Pura. Trad. Alexandre Fradique Morujão. Lisboa: Fundação Calouste Gulbenkian, 1985.

Prolegómenos a toda a Metafísica Futura que queira apresentar-se como ciência. Trad. Artur Morão. Lisboa: Edições 70, 1988. Lógica de Immanuel Kant. Um Manual para

Prelecções. Trad. Guido António de Almeida. Rio de Janeiro: Tempo Brasileiro, 1992.

\section{Bibliografia auxiliar:}

ALVES, Pedro. Studia Kantiana. Interpretação e crítica. Lisboa: CFUL, 2009

BARATA-MOURA, José. O outro Kant. Lisboa: CFUL, 2007.

DELEUZE, Gilles. A Filosofia crítica de Kant. Trad. Germiniano Franco. Lisboa: Edições 70, 2000.

PHILONENKO, Alexis. L'œuvre de Kant - La philosophie critique, Tomo I. Paris: Vrin, 2003 